\title{
EARLY INITIATION OF ANTI-TNF IS ASSOCIATED WITH FAVOURABLE LONG-TERM OUTCOME IN CROHN'S DISEASE: 10-YEAR-FOLLOW-UP DATA FROM THE SWISS IBD COHORT STUDY
}

\author{
Roy Frei ${ }^{1}$, Nicolas Fournier ${ }^{2}$, Jonas Zeitz ${ }^{1,3}$, Michael Scharl ${ }^{1}$, \\ Bernhard Morell ${ }^{1}$, Thomas Greuter ${ }^{1}$, Philipp Schreiner ${ }^{1}$, Benjamin \\ Misselwitz ${ }^{1}$, Ekaterina Safroneeva ${ }^{4}$, Alain M. Schoepfer ${ }^{5}$, Stephan R.

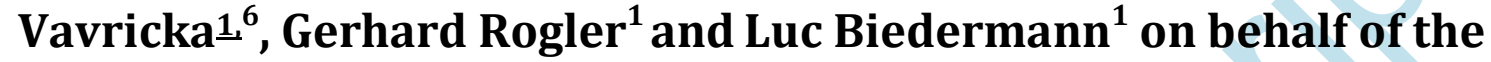 \\ Swiss IBD Cohort Study Group*
}

\author{
1 Department of Gastroenterology, University Hospital Zurich (USZ) and University of Zurich, \\ Raemistrasse 100, 8091 Zurich, Switzerland \\ 2 Institute of Social and Preventive Medicine (IUMSP), Lausanne University Hospital, Biopôle 2, \\ Route de la Corniche 10, 1010 Lausanne, Switzerland \\ 3 Center of Gastroenterology, Clinic Hirslanden, Zurich, Switzerland \\ 4 Institute of Social and Preventive Medicine, University of Bern, Finkenhubelweg 11, 3012 \\ Bern, Switzerland \\ 5 Division of Gastroenterology and Hepatology, Centre Hospitalier Universitaire Vaudois \\ (CHUV) and University of Lausanne, Lausanne, Switzerland \\ 6 Center of Gastroenterology and Hepatology, Zurich, Vulkanplatz 8, 8048 Zurich, Switzerland
}

Corresponding author: Roy Frei, Department of Gastroenterology, University Hospital Zurich (USZ) and University of Zurich, Raemistrasse 100, 8091 Zurich, Switzerland; email: roy.frei@bluewin.ch

Non-standard abbreviations:

Swiss Inflammatory Bowel Disease Cohort Study (SIBDCS)

Swiss National Science Foundation (SNSF)

Immunosuppressive agents (IM)

Extraintestinal manifestations (EIM)

Intestinal lymphoma (IL)

Copyright (C) 2019 European Crohn's and Colitis Organisation (ECCO). Published by Oxford University Press. All rights reserved. For permissions, please email:

journals.permissions@oup.com 
Manuscript Doi: 10.1093/ecco-jcc/jjz057

Colorectal cancer (CRC) 


\section{Abstract}

\section{Background and Aims}

The optimal timing of treatment escalation in Crohn's disease (CD) remains a challenge and very little is known about its long-term development following early versus late administration of anti-TNF antibodies. The long-term outcome of Swiss CD patients was comparatively assessed in an up to 10-year follow-up, using patients participating in the Swiss Inflammatory Bowel Disease Cohort Study (SIBDCS).

\section{$\underline{\text { Methods }}$}

Prospectively-collected SIBDCS patient data, including disease history, baseline characteristics at enrolment and course of disease were analysed in patients with early versus late ( $<24$ versus $>=24$ months after diagnosis $)$ and no anti-TNF treatment.

\section{$\underline{\text { Results }}$}

A reduced risk of developing bowel stenosis was found in patients who received early antiTNF treatment. This association was seen in patients overall and also in the subgroups of CD patients without pre-existing complications (Log-rank test: $\mathrm{p}<0.001$ ).

Furthermore, osteoporosis and anaemia were observed significantly less frequently in patients who received early anti-TNF treatment, compared to either patients who received treatment late $(\mathrm{p}<0.001$ and $\mathrm{p}=0.046$, respectively) or were never $(\mathrm{p}<0.001$ for both) treated with anti-TNF antibodies. Patients with early anti-TNF administration sought medical consultations significantly less often, including gastroenterologists in private practice $(\mathrm{p}=0.017)$, ambulatory (outpatient) hospital visits $(\mathrm{p}=0.038)$ and a composite of any medical visits $(p=0.001)$. The percentage of patients unable to work was lowest for early anti-TNF treated patients, in comparison to patients who were treated late or never (3.6\% versus $8.8 \%$ versus $3.7 \%, p=0.016$ ).

\section{$\underline{\text { Conclusions }}$}


Early anti-TNF administration was found to be associated with several indicators of a more favourable long-term outcome, in CD patients within the SIBDCS.

\section{$\underline{\text { Key words }}$}

anti-TNF, early intervention, long-term outcome 


\section{Introduction}

The optimal management of patients suffering from chronic inflammatory illnesses such as Crohn's disease (CD), has not been clarified and remains a matter for ongoing research. A major challenge lies in predicting the future course of the disease, which is difficult or even impossible, with the tools currently available in clinical practice [1].

However, the approval of anti-tumour necrosis factor (TNF) drugs in 1998 was an important breakthrough in CD therapy [2].

The substantial value of anti-TNF drugs was soon realized, and new possibilities for disease control seemed achievable. The TNF inhibitors' strong, anti-inflammatory activity made it possible to use a 'treat to target' approach for treating patients, aimed at going beyond mere symptom surveillance and clinical remission, to complete control of inflammation [3]. Individualised therapies might be state of the art even in the nearer future. A potentially beneficial impact of anti-TNF drugs on the progress of the disease's course, was indicated in both animal [4] and cohort studies in humans [5-7].

In addition, several studies have compared 'step-up' and 'top-down' treatment strategies in CD [8-10]. The current literature favours a 'rapid step-up' strategy, with early, stepwise introduction of immunosuppressive agents (IM) and the timely addition of anti-TNF [11-14], although the benefit of early IM remains controversial $[13,15]$. The impact of a 'top-down' strategy, with early introduction of anti-TNF, including the key question, whether the disease's course can be modified through early anti-TNF administration has been investigated by even more studies [4, 16-24].

However, the evidence for a potentially beneficial impact on the disease's course and knowledge about the proper selection of patients in need of an early, aggressive treatment, remains limited. In particular, the disease's long-term development beyond the usual observation periods of one year, in most studies, or 5 years in very few instances, remains unknown.

Using the prospectively obtained data from patients participating in the SIBDCS, the study aimed to investigate whether early anti-TNF administration, defined as initiation during the first 24 months after CD diagnosis, is associated with beneficial effects on predefined outcome parameters in $\mathrm{CD}$, compared to patients with anti-TNF initiation later than the first 24 months since diagnosis or patients without anti-TNF treatment. 
Manuscript Doi: 10.1093/ecco-jcc/jjz057 


\section{Materials and Methods}

\section{Study Population:}

The nationwide inclusion of IBD patients into the SIBDCS began in 2006. The SIBDCS was designed as a prospective cohort study. All the patients provided written, informed consent for participation in the study at enrolment. SIBDCS receives ongoing supporting grants from the Swiss National Science Foundation (SNSF) and has been approved by all participating centres' local ethical committees. SIBDCS has been described in detail by Pittet et al. [25, 26].

At the time of inclusion into the study, the patients and the treating physicians completed enrolment questionnaires. The patient questionnaires contained questions about the individual perception of the clinical course of the disease, the severity of symptoms, as well as quality of life (QoL), and socioeconomic associations. The physician questionnaires focused on clinical characteristics, the classification and course of IBD. Both patients and treating physicians are followed up annually by follow-up questionnaires similar to the original inclusion questionnaires.

Data from all the CD patients enrolled into SIBDCS since its start in 2006, have been used for the analysis in this study. Data extraction, from the SIBDCS data base, as well as the subsequent statistical analysis, were performed at the SIBDCS data centre in Lausanne, Switzerland.

\section{Data extractions, definitions:}

All the data for this study were collected prospectively through the SIBDCS cohort study and analysed retrospectively at the cut-off date: $12 / 31 / 2016$ for our study. Anti-TNF medication was defined as the administration of at least one dose of the three anti-TNF agents currently approved for the treatment of CD in Switzerland, i.e. infliximab, adalimumab or certolizumab pegol, during the observation period.

Three groups were defined in order to assess the impact of the timing of anti-TNF administration on the course of the disease: 'early anti-TNF', i.e. patients who received anti-TNF within the first 24 months following diagnosis; 'late anti-TNF', i.e. patients who received antiTNF medication more than 24 months after diagnosis and 'no anti-TNF', i.e. patients who received no anti-TNF therapy following IBD diagnosis during the observation period. 
The study's primary outcomes included bowel stenosis, perianal fistula, other fistula, any fistula, perianal surgery, intestinal surgery, any surgery and extraintestinal manifestations (EIM). These outcome parameters were analysed using the log-rank test, looking at the time to the first complication. Secondary outcomes included the occurrence of osteoporosis and anaemia, utilization of health care resources and inability to work because of CD (absence from work due to other reasons was not included in these analyses). The rates of occurrence of secondary outcomes between different treatment groups were compared.

Safety data included rates and differences in occurrence of colorectal cancer (CRC) and intestinal lymphomas (IL). In addition, the rates of opportunistic infections leading to the cessation of antiTNF therapy, were also assessed.

In the survival analysis for the primary outcomes, patients who were treated early $(<24$ months), were compared with patients who were treated with anti-TNF agents later $(>=24$ months). Pre-existing complications, which were analysed as primary outcomes during followup after anti-TNF induction, were defined as any single occurrence or a continuance of the same complications which already existed prior to anti-TNF induction.

There is a lack of standardized definitions for bowel stenosis, which a very recent expert consensus has aimed to overcome. According to this consensus, the best current definition of small bowel stricture is based on a combination of wall thickening, luminal narrowing and prestenotic dilation [27]. In conjunction with these parameters, the assessment of clinical symptoms and signs, radiological examinations and endoscopy were used to diagnose bowel stenosis in this study.

'Perianal fistula' refers to any kind of fistula located in the perianal area, such as submucosal, intersphincteric, transsphincteric, suprasphincteric or extrasphincteric fistulas. 'Other fistula' refers to any kind of non-perianal fistula, whereas 'any fistula' combines perianal and all kinds of non-perianal fistula. Likewise, 'perianal surgery' refers to perianal surgical procedures, such as drainage of perianal abscesses, seton-placement or any form of fistula extraction/closure procedure, whereas 'intestinal surgery' refers to any kind of CD-related surgery performed on the intestine, including any kind of resection or ostomy surgery. Again, 'any surgery' refers to the need for any CD-related surgery, irrespective of the location or type of procedure.

EIM includes peripheral arthritis/arthralgia, uveitis/iritis, pyoderma gangrenosum, erythema nodosum, aphthous oral ulcers/stomatitis, ankylosing spondylitis (Bechterew), sacroiliitis and primary sclerosing cholangitis. 
Regarding secondary outcomes osteoporosis and anaemia were assessed due to their clinical relevance.

Furthermore, the study tested for differences in the utilization of health care resources across treatment groups. Therefore, CD-related medical visits to general practitioners, gastroenterologists in private practice, ambulatory visits to hospitals and hospitalisations were assessed. The category 'other' includes medical visits to any physician not included in the predefined categories above, for example specialised surgeons such as coloproctologists. The data on utilization of health care resources was collected in every patient questionnaire and took the last three months of each annual follow-up questionnaire into account. The three months recall period was chosen in cooperation with experts in public health and psychologists, which have been involved in the SIBDCS from the very beginning until now. The three-monthinterval was considered optimal for minimizing the risk of recall bias and inadequate data.

Like data on utilization of health care resources, data on ability to work was also assessed with every annual patient questionnaire for the last three months antecedent to the follow-up.

\section{Statistical Analysis}

All statistical analyses were carried out using the Stata Software (v. 14.2, StataCorp, College Station, TX, USA).

Categorical data were summarized as raw frequencies and relative percentages. Differences in categorical data distribution between two or more independent groups were assessed using the chi-squared test, or the Fisher's exact test in case of low sample size.

Continuous data distribution was assessed using normal, quantile-quantile (QQ)-plots. Gaussian distributed data were summarized as mean, standard deviation (SD) and range, while nonGaussian distributed data were summarized as median, interquartile range (IQR) and range. Differences in means for Gaussian distributed data between two independent groups were assessed using the Student's t-test, or ANOVA, for more than two independent groups. Differences in distribution of non-Gaussian distributed data between two independent groups, were assessed using the Wilcoxon-Mann-Whitney rank-sum test, or the Kruskall-Wallis test for more than two groups.

The primary outcomes were analysed as time-to-event data. The complication-free proportions according to time, were derived using Kaplan-Meyer survival estimator. The log-rank test was 
Manuscript Doi: 10.1093/ecco-jcc/jjz057

used to assess overall differences between survival curves for independent groups. A p-value $<=$ 0.05 was considered to be statistically significant. 


\section{Results}

\section{Study population}

During the ten-year period, from the start of patients' inclusion into SIBDCS in early 2006 until the 31 $1^{\text {st }}$ of December 2016, a total of 1707 adult CD patients were enrolled, and 1592 patients' data could be analysed (Figure 1). The study population's demographic data and clinical characteristics are shown in Table 1.

It is notable that patients who had received early anti-TNF therapy were younger (median age 32 years vs. 44 years and 48 years, in late and no anti-TNF, respectively, $\mathrm{p}<0.001$ ) and had a shorter disease duration at the time of inclusion into the study, with a higher fraction of B1p phenotype.

In terms of complications, those patients with no given pre-existing complication prior to antiTNF induction, were younger and had a shorter disease duration and lower rate of other complications, compared to their counterparts who had a respective pre-existing complication.

However, for perianal surgery, there was no significant difference in age between patients with, compared to those without, perianal surgery prior to anti-TNF induction $(\mathrm{p}=0.067)$. There were also no significant differences in the presence of complications, other than EIM, between patients with or without EIM prior to anti-TNF induction ( $\mathrm{p}=0.084)$.

\section{Disease course and complications}

\section{$\underline{\text { Bowel stenosis }}$}

A reduced risk of developing stenosis was found in early anti-TNF treated patients, compared to late anti-TNF treated patients, by using Kaplan-Meier analysis, as shown in Figure 2 (log-rank test: $\mathrm{p}<0.001)$. This difference was most pronounced in the subgroups of CD patients without pre-existing complication (log-rank test: $\mathrm{p}<0.001$ ), whilst only by trend in patients with preexisting complication ( $\mathrm{p}=0.147$, Table 2). A significant difference between early and late antiTNF treated patients, was also detected when pre-existing complications were not considered $(\mathrm{p}<0.001$, Supplementary Table 1$)$. 
Amongst those patients without bowel stenosis as a pre-existing complication, a larger number of early anti-TNF treated patients were free from the complication 2, 5 and 10 years after antiTNF initiation (95.1\%, 83.6\% and 67.8\%, respectively), than late anti-TNF treated patients (88.1\%, 68.2\% and 45.7\%, Supplementary Table 2).

\section{Penetrating complications and surgery}

Although a global difference was observed in the need for perianal surgery across the patient groups overall ( $p=0.002$, Table 2 ), this difference was predominantly seen between patients with, compared to those without, pre-existing complications and was not dependent to early versus late anti-TNF treatment (Supplementary Figure 1).

In addition, there were no significant differences favouring early intervention in terms of either intestinal or perianal surgery, nor for the occurrence of perianal fistula or fistula overall (Table 2).

Amongst those patients without any pre-existing penetrating complication or surgery, a larger number of early anti-TNF treated patients were still free from penetrating complications and surgeries 10 years after anti-TNF initiation (60.1\%,68.2\%, 70.8\% and 83.4\%, respectively), compared to late anti-TNF treated patients $(50.7 \%, 63.6 \%, 57.2 \%$ and $75.6 \%$, Supplementary Table 2).

\section{$\underline{\text { Extraintestinal manifestations }}$}

No difference was observed in the development of EIM, between early versus late anti-TNF treated patients without pre-existing complications (Supplementary Figure 2). However, early treated patients with pre-existing complications appeared to develop less EIM by trend $(\mathrm{p}=0.087$, Table 2$)$.

When considering EIM as a pre-existing complication, a larger number of early anti-TNF treated patients were still free from EIM 2, 5 and 10 years after anti-TNF initiation $(75.0 \%, 49.8 \%$ and $26.3 \%$, respectively), compared to late anti-TNF treated patients $(74.7 \%, 46.8 \%$ and $22.1 \%$, Supplementary Table 2).

\section{Osteoporosis and anaemia}


Osteoporosis and anaemia were observed significantly less frequently in early versus late antiTNF treated patients ( $p<0.001$ and $p=0.046$, respectively, Supplementary Table 3, Figure 3).

\section{Medical consultations and hospitalisations}

Patients who were administered anti-TNF early, needed medical consultations less often, including consultations with a gastroenterologist in private practice $(\mathrm{p}=0.017)$, ambulatory hospital visits $(\mathrm{p}=0.038)$ or a composite of any medical visits at all $(\mathrm{p}=0.001)$. There was, however, no difference in visits to a general practitioner or any other CD-related medical visits.

Overall hospitalisations differed between the three groups tested, with the lowest number of hospitalisations in the group of patients who had never been treated with anti-TNF $(p=0.001$, Supplementary Table 4). However, there was no difference in hospitalisation rates between patients with early versus late, anti-TNF administration (Figure 4).

\section{Absence from work}

TNF treatment influenced work disability due to CD across all treatment groups $(\mathrm{p}=0.016$, Supplementary Table 5). Early-treated patients were by trend, less likely to be unable to work, with $3.6 \%$ of patients being absent from work, compared to $8.8 \%$ of late-treated patients ( $p=0.096$, Supplementary Table 5, Figure 5).

\section{Safety}

There were no significant differences in CRC or IL between the three different treatment groups (Supplementary Table 6). The absolute number of patients observed for whom opportunistic infection led to therapy cessation, was very low, with 1 patient $(0.4 \%)$ from the early and 4 patients $(0.6 \%)$ from the late treatment group (Supplementary Figure 3). 


\section{Discussion}

In this study, an association was demonstrated between early anti-TNF administration and a reduced risk of developing bowel stenosis. In addition, patients with any pre-existing complication were relatively protected from a recurrence of this outcome 5 and 10 years after early versus late anti-TNF initiation, respectively.

In particular, osteoporosis and anaemia were observed less frequently in the group of patients who received early anti-TNF treatment. Furthermore, patients with early anti-TNF administration sought medical consultations less frequently and by trend, showed lower rates of absence from work due to $\mathrm{CD}$, compared to patients with late anti-TNF administration.

In terms of stricturing disease behaviour, the study's findings are in line with a previous SIBDCS study, in which a significant association between IM or anti-TNF agents and reduced bowel stenosis, was observed [16].

As well as having a preventive effect, anti-TNF agents might also be effective in patients with established fibrotic disease. This has previously been suggested in a study by Allocca et al. [28] on stricturing $\mathrm{CD}$, which showed that anti-TNF agents might prevent surgery in up to two-thirds of patients with intestinal stenosis. The beneficial effects of early anti-TNF administration seem to be selective for bowel stenosis, as neither the current study nor the previous investigations identified any effects on the overall need for surgery in CD [29-31].

The reason why, in this study, stricturing disease appears to be more prone to modulation by early anti-TNF administration, as compared to penetrating disease, remains both unclear and also controversial. Some of the other recently published studies on this topic even indicated the opposite, showing that anti-TNF therapy might prevent the development of penetrating (B3) but not stricturing (B2), disease migration [32-34].

A possible explanation for the present study's findings might be that bowel stenosis and scar tissue formation result from the long-term, cumulative effects of continuous inflammation. Stopping or attenuating of inflammation at an early stage, might therefore prevent the ongoing progression of scar tissue formation, wall thickening, luminal narrowing and thus the development of stenosis over time [35-37]. In contrast, penetrating disease might manifest more suddenly at any time in the course of the disease [38], turning it out to be less susceptible to modification by early anti-TNF treatment.

According to this study's results, the overall need for surgery doesn't appear to be affected by the timing of the anti-TNF intervention. This is in line with previous studies [39], which indicate 
that the early use of anti-TNF can positively affect symptoms of stenosis but even though risk factors can be identified [40], might not yet be an appropriate strategy for reducing surgical interventions [30, 31, 41, 42].

In contrast to this, a retrospective analysis of Korean CD patients found significantly longer times to intestinal surgery $(\mathrm{p}<0.001)$, stricturing complications $(\mathrm{p}=0.002)$, and penetrating complications $(\mathrm{p}<0.001)$ in the early anti-TNF/ IM groups, compared to the late treatment group [43].

The development of EIM does not seem to be affected by the timing of anti-TNF administration. In addition, pre-existing EIM does not seem to be affected differently by early or late, anti-TNF intervention.

There are, however, studies about EIM and IBD phenotypes and medication, also including studies within the SIBDCS, which indicate that the presence of EIM is often associated with active disease, positive family history or treatment strategy (higher AZA exposure) [44, 45]. Nonetheless, to the best of the authors' knowledge, there are no studies which address the best point in time for the administration of anti-TNF, regarding the development of EIM.

In the present study, early anti-TNF administration was associated with a lower risk of osteoporosis, which remains a frequent problem in IBD patients [46]. In the past, infliximab therapy has been associated with increased biochemical markers for bone formation without increasing bone resorption [47]. Whether this might be due to a direct beneficial effect of TNF blockade on bone turnover, a beneficial effect on CD activity, resulting in decreased glucocorticoid exposure, or both, remains difficult to determine, especially as osteoporosis was not a primary outcome of this study.

Early anti-TNF administration was found to be associated with a lower risk of anaemia. Shortterm anti-TNF therapy might significantly improve iron metabolism and, subsequently, anaemia in IBD [48]. This effect appears to be primarily related to the modulation of the cytokine network, leading to a relevant decrease of hepcidin, a master regulator of anaemia in chronic disease. On the other hand, during long-term treatment, anti-TNF therapy might also improve iron deficiency anaemia by inducing mucosal healing.

The study identified a lower need for consultations with gastroenterologists in private practice and hospital outpatient visits in the early treatment group, but not for hospitalisation rates and general practitioner consultations. In a systemic review [49] which assessed the reduction in hospitalisation rates, as well as surgery rates, through immunosuppressive therapy, anti-TNF 
agents reduced the probability of hospitalisation by half. The results of another investigation, revealing an association between timely anti-TNF administration and decrease in hospitalisation rates, are even more encouraging [50].

There are only few studies investigating absence from work due to CD in relation to medical therapy [51-56], and to the best of the authors' knowledge, no study has so far addressed the effects of anti-TNF treatment timing on CD-related work disability. This study showed significantly lower rates of absence from work for early anti-TNF treated CD patients, compared to late treated patients and an even slightly lower rate of work disability, compared to patients who have never been treated with anti-TNF.

With the increasing availability of newer agents for treating IBD, the questions of positioning and determining the best timepoint during the course of the individual patient's disease is becoming more immediate. Moving beyond anti-TNF, a multicentre, open-label phase IV trial (LOVE-CD; NCT02646683), is currently recruiting patients with CD; it aims to investigate whether there is a difference in clinical and endoscopic remission at week $26\left(1^{\circ} \mathrm{EP}\right)$ between patients receiving early ( $<24$ months after diagnosis) versus late primary administration of vedolizumab. Similar studies which also consider complication rates, are desirable for other, newer agents, including ustekinumab and JAK-inhibitors.

Our study has several strengths and limitations. One limitation is that, CD patients from tertiary care hospitals are over-represented within SIBDCS and the SIBDCS patient population cannot be considered to be fully population-based, as there is presumably a preponderance of patients with more severe disease. Moreover, data collected using questionnaires may be linked to a risk of bias, above all reporting and recall biases. Furthermore, no detailed data are available on the anti-TNF administration, in terms of individual doses and time intervals. The patient numbers in some of the subgroups analysed are rather small. This particularly applies to patients with early anti-TNF intervention and pre-existing complication of the respective outcome parameter. Nevertheless, those patient groups were kept in the analysis as the authors believe that they provide interesting information. Overall, it must be emphasized that the current investigation may not be sufficiently powered for any robust conclusions to be drawn with regards to the risk benefit balance for early anti-TNF administration. In terms of risks, severe adverse events (e.g. major infections requiring ICU or melanoma) have a tremendous impact but are fortunately infrequent. Due to the latter, a larger study population or large (multinational) patient registries would be advantageous. In addition, all the study's findings represent associations and the underlying causes and effects remain the subject of speculation. Prospective, randomized longterm studies would be needed to provide definite answers. However, such trials are virtually 
impossible to perform. Therefore, prospective cohort studies are an adequate means of addressing the potential impact of early anti-TNF administration on the course of disease. The rigorous, annual follow-up, with detailed physician and patient questionnaires, is one of the study's strengths. In addition, the long prospective follow-up period of up to 10 years, is another important strength.

Furthermore, the present study may even have underestimated the benefit of early anti-TNF administration, since patients in the no anti-TNF group might have been positively selected because of having a less severe disease course (as indicated by several outcome parameters with apparently beneficial results for this group, including Crohn's Disease Activity Index (CDAI) score, rates of hospitalisation, perianal fistula formation and perianal surgery). In view of this, the reduction in bowel stenosis, lower rates of osteoporosis and anaemia, fewer absences from work due to $\mathrm{CD}$ and fewer ambulatory hospital visits in the early treatment group shown by our study, indicate a truly beneficial effect.

Importantly, one of the biggest risk factors for the development of any complication, appeared to be a prior history of exactly that complication. Regarding this factor, patients with or without a history of the respective complication were considered separately in the survival analysis, to distinguish the different preconditions in time to event.

In conclusion, an association was observed between early anti-TNF administration and several beneficial clinical outcomes in $\mathrm{CD}$, including reduced risks of bowel stenosis, osteoporosis and anaemia. In addition, lower rates of medical consultations and absences from work due to CD, were observed following early anti-TNF treatment. Accordingly, patients with a stricturing type (B2) or at risk of developing such a phenotype (i.e. those with long-segment or multi-segmental small bowel inflammatory lesions), might benefit most from an early anti-TNF intervention. The results therefore highlight the importance of properly identifying patients in need of early antiTNF administration, which currently remains a big challenge for the practicing clinicians, in the absence of high-accuracy tools for predicting the future course of CD. 


\section{Funding}

This work was supported by research grants from the Swiss National Science Foundation to GR [Grant No.310030- 120312], and the Swiss IBD Cohort [Grant No. 3347CO-108792].

\section{Conflict of interest}

RF: none to declare; NF: none to declare; JZ: none to declare; MS: none to declare; BMO: none to declare; TG: grants from Swiss National Science Foundation, grants from Swiss National Science Foundation, grants from Swiss National Science Foundation, grants from Swiss National Science Foundation, during the conduct of the study; other from Falk Foundation, other from Vifor, other from Atlantic Healthcare, personal fees from Sanofi, grants from Novartis, outside the submitted work; PS: other from Vifor, other from Pfizer, other from UBC, outside the submitted work; BMI: personal fees from Gilead, grants and personal fees from MSD, personal fees from Novigenix, personal fees from Vifor, personal fees from Novartis, outside the submitted work; ES: none to declare; ES: none to declare; AS: none to declare; SV: grants from MSD, Abbvie, Vifor, Takeda, personal fees from MSD, Abbvie, Vifor, Takeda, UCB, Tillots, Ferring, Falk, Pfizer; GR: consulted to Abbot, Abbvie, Augurix, Boehringer, Calypso, FALK, Ferring, Fisher, Genentech, Essex/MSD, Novartis, Pfizer, Phadia, Roche, UCB, Takeda, Tillots, Vifor, Vital Solutions and Zeller; received speakers honoraria from Astra Zeneca, Abbott, Abbvie, FALK, MSD, Phadia, Tillots, UCB, and Vifor; received educational grants and research grants from Abbot, Abbvie, Ardeypharm, Augurix, Calypso, Essex/MSD, FALK, Flamentera, Novartis, Roche, Takeda, Tillots, UCB and Zeller; LB: grants from Swiss National Science Foundation, during the conduct of the study; personal fees from Abbvie, personal fees from MSD, personal fees from Vifor, personal fees from Abbvie, personal fees from Ferring, personal fees from MSD, personal fees from Pfizer, personal fees from Shire, personal fees from Takeda, personal fees from UCB, personal fees from ThermoFisher, personal fees from Janssen, outside the submitted work. 


\section{Acknowledgments}

We acknowledge all IBD patients participating in the SIBDCS for sharing their medical history and symptoms, and regularly responding to the cohort questionnaires. Furthermore, we would like to acknowledge the data centre of SIBDCS for careful and labour-intensive data collection.

\section{Authors' Contributions}

RF, LB, NF, and GR formed the concept of the study. NF, LB, RF and GR performed preevaluations for data extraction from the SIBDCS. LB, BMI, and RF carried out first analyses of data. NF, RF and LB performed the final statistical analysis. RF drafted the manuscript. LB, RF, NF and GR wrote the manuscript. RF, LB, NF, GR, JZ, MS, BM, TG, PS, BM, ES, AS and SV read the final manuscript, gave critical input, and approved the final manuscript.

Conference presentation: European Crohn's and Colitis Organisation [ECCO] 2018; Digestive Disease Week [DDW] 2018. 


\section{References}

1. Lakatos, P.L. and L.S. Kiss, Is the disease course predictable in inflammatory bowel diseases? World J Gastroenterol, 2010. 16(21): p. 2591-9.

2. Targan, S.R., et al., A short-term study of chimeric monoclonal antibody cA2 to tumor necrosis factor alpha for Crohn's disease. Crohn's Disease cA2 Study Group. N Engl J Med, 1997. 337(15): p. 1029-35.

3. Colombel, J.F., et al., Effect of tight control management on Crohn's disease (CALM): a multicentre, randomised, controlled phase 3 trial. Lancet, 2017.

4. Schmiedlin-Ren, P., et al., Anti-TNFalpha alters the natural history of experimental Crohn's disease in rats when begun early, but not late, in disease. Am J Physiol Gastrointest Liver Physiol, 2016. 311(4): p. G688-G698.

5. Gower-Rousseau, C., et al., Are we improving disease outcomes in IBD? A view from the epidemiology side. Gut, 2014. 63(10): p. 1529-30.

6. Nguyen, G.C., et al., Outcomes of patients with Crohn's disease improved from 1988 to 2008 and were associated with increased specialist care. Gastroenterology, 2011. 141(1): p. 907.

7. Magro, F., et al., Is it possible to change phenotype progression in Crohn's disease in the era of immunomodulators? Predictive factors of phenotype progression. Am J Gastroenterol, 2014. 109(7): p. 1026-36.

8. Hanauer, S.B., Clinical perspectives in Crohn's disease. Turning traditional treatment strategies on their heads: current evidence for "step-up" versus "top-down". Rev Gastroenterol Disord, 2007. 7 Suppl 2: p. S17-22.

9. Hoekman, D.R., et al., 924 Long-Term Outcomes of Top-Down Versus Step-up Treatment in Newly Diagnosed Crohn's Disease: Final Data. Gastroenterology, 2015. 148(4, Supplement 1): p. S-176.

10. Lin, M.V., W. Blonski, and G.R. Lichtenstein, What is the optimal therapy for Crohn's disease: step-up or top-down? Expert Rev Gastroenterol Hepatol, 2010. 4(2): p. 167-80.

11. Picco, M.F., et al., Immunomodulators are associated with a lower risk of first surgery among patients with non-penetrating non-stricturing Crohn's disease. Am J Gastroenterol, 2009. 104(11): p. 2754-9.

12. Ordas, I., B.G. Feagan, and W.J. Sandborn, Early use of immunosuppressives or TNF antagonists for the treatment of Crohn's disease: time for a change. Gut, 2011. 60(12): p. 1754-63. 
13. Cosnes, J., et al., Early administration of azathioprine vs conventional management of Crohn's Disease: a randomized controlled trial. Gastroenterology, 2013. 145(4): p. 758-65 e2; quiz e14-5.

14. Khanna, R., et al., Early combined immunosuppression for the management of Crohn's disease (REACT): a cluster randomised controlled trial. Lancet, 2015. 386(10006): p. 1825-34.

15. Panes, J., et al., Early azathioprine therapy is no more effective than placebo for newly diagnosed Crohn's disease. Gastroenterology, 2013. 145(4): p. 766-74 e1.

16. Safroneeva, E., et al., Impact of the early use of immunomodulators or TNF antagonists on bowel damage and surgery in Crohn's disease. Aliment Pharmacol Ther, 2015. 42(8): p. 977-89.

17. Walters, T.D., et al., Increased effectiveness of early therapy with anti-tumor necrosis factor-alpha vs an immunomodulator in children with Crohn's disease. Gastroenterology, 2014. 146(2): p. 383-91.

18. Walters, T.D. and J.S. Hyams, Can early anti-TNF-alpha treatment be an effective therapeutic strategy in children with Crohn's disease? Immunotherapy, 2014. 6(7): p. 799802.

19. Miyoshi, J., et al., Early intervention with adalimumab may contribute to favorable clinical efficacy in patients with Crohn's disease. Digestion, 2014. 90(2): p. 130-6.

20. Ghazi, L.J., et al., Step up versus early biologic therapy for Crohn's disease in clinical practice. Inflamm Bowel Dis, 2013. 19(7): p. 1397-403.

21. Rubin, D.T., O. Uluscu, and R. Sederman, Response to biologic therapy in Crohn's disease is improved with early treatment: an analysis of health claims data. Inflamm Bowel Dis, 2012. 18(12): p. 2225-31.

22. Juillerat, P., et al., Appropriateness of early management of newly diagnosed Crohn's disease in a European population-based cohort. Scand J Gastroenterol, 2010. 45(12): p. 1449-56.

23. Fidder, H.H. and D.W. Hommes, Anti-TNF and Crohn's disease: when should we start? Curr Drug Targets, 2010. 11(2): p. 143-7.

24. Ricart, E., et al., Are we giving biologics too late? The case for early versus late use. World J Gastroenterol, 2008. 14(36): p. 5523-7.

25. Pittet, V., et al., Cohort profile: the Swiss Inflammatory Bowel Disease Cohort Study (SIBDCS). Int J Epidemiol, 2009. 38(4): p. 922-31.

26. Pittet, V., et al., Cohort Profile Update: The Swiss Inflammatory Bowel Disease Cohort Study (SIBDCS). Int J Epidemiol, 2019. 
27. Rieder, F., et al., An expert consensus to standardise definitions, diagnosis and treatment targets for anti-fibrotic stricture therapies in Crohn's disease. Aliment Pharmacol Ther, 2018. 48(3): p. 347-357.

28. Allocca, M., et al., Efficacy of tumour necrosis factor antagonists in stricturing Crohn's disease: A tertiary center real-life experience. Dig Liver Dis, 2017. 49(8): p. 872-877.

29. Kotze, P.G., et al., Comparison of time until elective intestinal resection regarding previous anti-tumor necrosis factor exposure: a Brazilian study on patients with Crohn's disease. Intest Res, 2018. 16(1): p. 62-68.

30. Rayen, J., et al., The long-term outcome of anti-TNF alpha therapy in perianal Crohn's disease. Tech Coloproctol, 2017. 21(2): p. 119-124.

31. de Groof, E.J., et al., Treatment of perianal fistula in Crohn's disease: a systematic review and meta-analysis comparing seton drainage and anti-tumour necrosis factor treatment. Colorectal Dis, 2016. 18(7): p. 667-75.

32. Kugathasan, S., et al., Prediction of complicated disease course for children newly diagnosed with Crohn's disease: a multicentre inception cohort study. Lancet, 2017. 389(10080): p. 1710-1718.

33. Jeuring, S.F., et al., Improvements in the Long-Term Outcome of Crohn's Disease Over the Past Two Decades and the Relation to Changes in Medical Management: Results from the Population-Based IBDSL Cohort. Am J Gastroenterol, 2017. 112(2): p. 325-336.

34. Gottgens, K.W., et al., Time trends in the epidemiology and outcome of perianal fistulizing Crohn's disease in a population-based cohort. Eur J Gastroenterol Hepatol, 2017. 29(5): p. 595-601.

35. Bodini, G., et al., Anti-TNF therapy is able to stabilize bowel damage progression in patients with Crohn's disease. A study performed using the Lemann Index. Dig Liver Dis, 2017. 49(2): p. 175-180.

36. Pallotta, N., et al., Effect of infliximab on small bowel stenoses in patients with Crohn's disease. World J Gastroenterol, 2008. 14(12): p. 1885-90.

37. Chang, C.W., et al., Intestinal stricture in Crohn's disease. Intest Res, 2015. 13(1): p. 19-26.

38. Scharl, M. and G. Rogler, Pathophysiology of fistula formation in Crohn's disease. World J Gastrointest Pathophysiol, 2014. 5(3): p. 205-12.

39. Kerur, B., et al., Biologics Delay Progression of Crohn's Disease, but Not Early Surgery, in Children. Clin Gastroenterol Hepatol, 2018.

40. Manser, C.N., et al., Risk factors for repetitive ileocolic resection in patients with Crohn's disease: results of an observational cohort study. Inflamm Bowel Dis, 2014. 20(9): p. 1548-54. 
41. Bouguen, G., et al., Long-term outcome of perianal fistulizing Crohn's disease treated with infliximab. Clin Gastroenterol Hepatol, 2013. 11(8): p. 975-81 e1-4.

42. Yarur, A.J., et al., Higher infliximab trough levels are associated with perianal fistula healing in patients with Crohn's disease. Aliment Pharmacol Ther, 2017. 45(7): p. 933940.

43. Oh, E.H., et al., Early anti-TNF/immunomodulator therapy is associated with better longterm clinical outcomes in Asian patients with Crohn's disease with poor prognostic factors. PLoS One, 2017. 12(5): p. e0177479.

44. Vavricka, S.R., et al., Frequency and risk factors for extraintestinal manifestations in the Swiss inflammatory bowel disease cohort. Am J Gastroenterol, 2011. 106(1): p. 110-9.

45. Vegh, Z., et al., Association of extraintestinal manifestations and anaemia with disease outcomes in patients with inflammatory bowel disease. Scand J Gastroenterol, 2016. 51(7): p. 848-54.

46. Schule, S., et al., Prediction of low bone mineral density in patients with inflammatory bowel diseases. United European Gastroenterol J, 2016. 4(5): p. 669-676.

47. Abreu, M.T., et al., Treatment with infliximab is associated with increased markers of bone formation in patients with Crohn's disease. J Clin Gastroenterol, 2006. 40(1): p. 55-63.

48. Cavallaro, F., et al., Anti-TNF-Mediated Modulation of Prohepcidin Improves Iron Availability in Inflammatory Bowel Disease, in an IL-6-Mediated Fashion. Can J Gastroenterol Hepatol, 2017. 2017: p. 6843976.

49. Mao, E.J., et al., Systematic review with meta-analysis: comparative efficacy of immunosuppressants and biologics for reducing hospitalisation and surgery in Crohn's disease and ulcerative colitis. Aliment Pharmacol Ther, 2017. 45(1): p. 3-13.

50. Mandel, M.D., et al., Decreasing trends in hospitalizations during anti-TNF therapy are associated with time to anti-TNF therapy: Results from two referral centres. Dig Liver Dis, 2014. 46(11): p. 985-90.

51. van der Have, M., et al., Self-reported disability in patients with inflammatory bowel disease largely determined by disease activity and illness perceptions. Inflamm Bowel Dis, 2015. 21(2): p. 369-77.

52. Ramos, A., et al., IBD-related work disability in the community: Prevalence, severity and predictive factors. A cross-sectional study. United European Gastroenterol J, 2015. 3(4): p. $335-42$.

53. van der Valk, M.E., et al., Risk factors of work disability in patients with inflammatory bowel disease--a Dutch nationwide web-based survey: work disability in inflammatory bowel disease. J Crohns Colitis, 2014. 8(7): p. 590-7.

54. Israeli, E., et al., Low prevalence of disability among patients with inflammatory bowel diseases a decade after diagnosis. Clin Gastroenterol Hepatol, 2014. 12(8): p. 1330-7 e2. 
55. Hoivik, M.L., et al., Work disability in inflammatory bowel disease patients 10 years after disease onset: results from the IBSEN Study. Gut, 2013. 62(3): p. 368-75.

56. Siebert, U., et al., Predictors of temporary and permanent work disability in patients with inflammatory bowel disease: results of the swiss inflammatory bowel disease cohort study. Inflamm Bowel Dis, 2013. 19(4): p. 847-55. 


\section{Figures and Tables}

\section{Figures}



Figure 1: Flowchart Study Population 

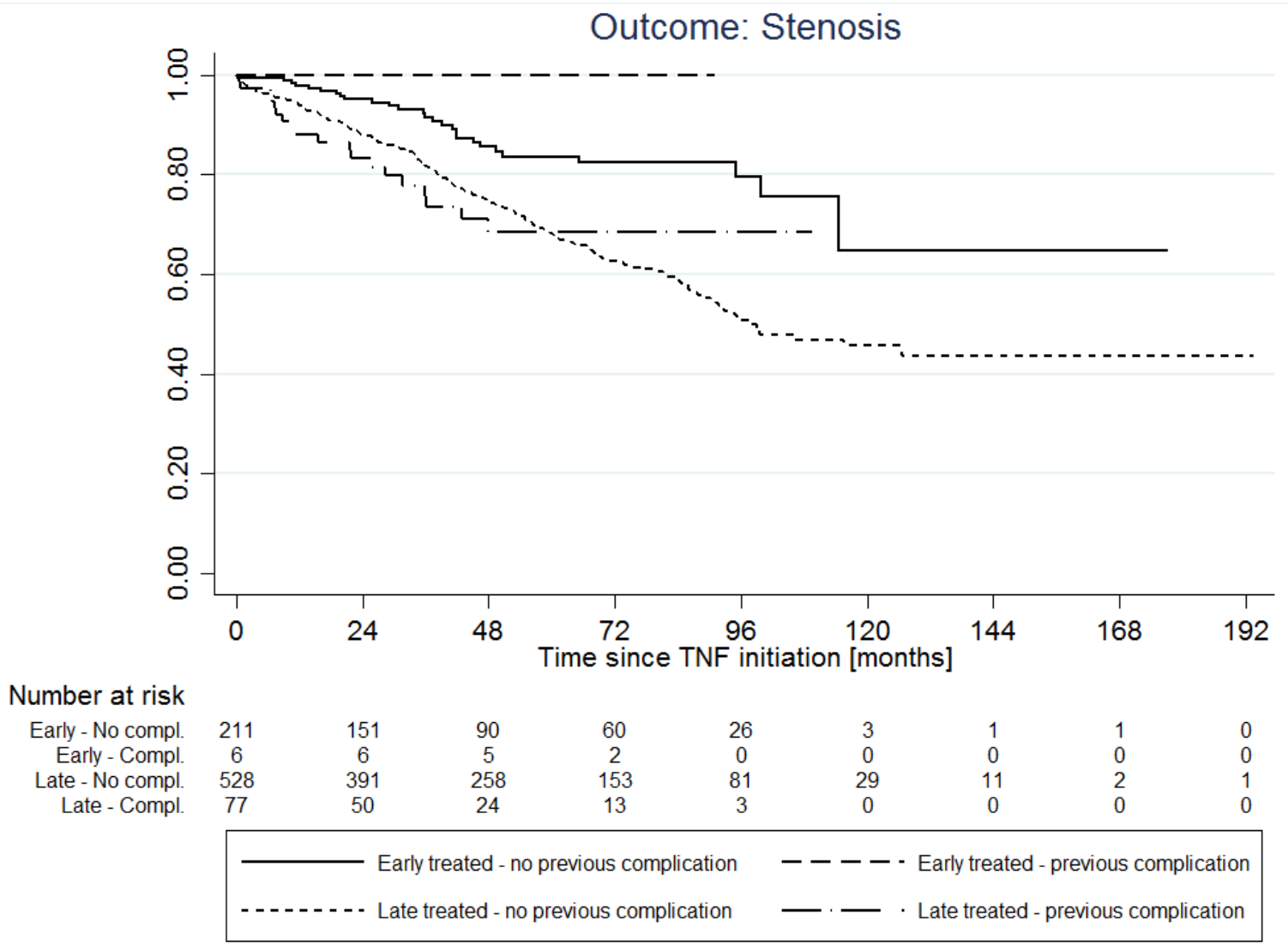

Logrank test: Global: $p<0.001$; Early vs Late (w/o complication): $p<0.001$; Early vs Late (w/ complication): $p=0.147$.

Figure 2: Kaplan-Meier curves showing freedom from developing new bowel stenosis in patients treated early with anti- TNF agents compared to patients treated late with anti- TNF agents, with or without history of previous bowel stenosis 


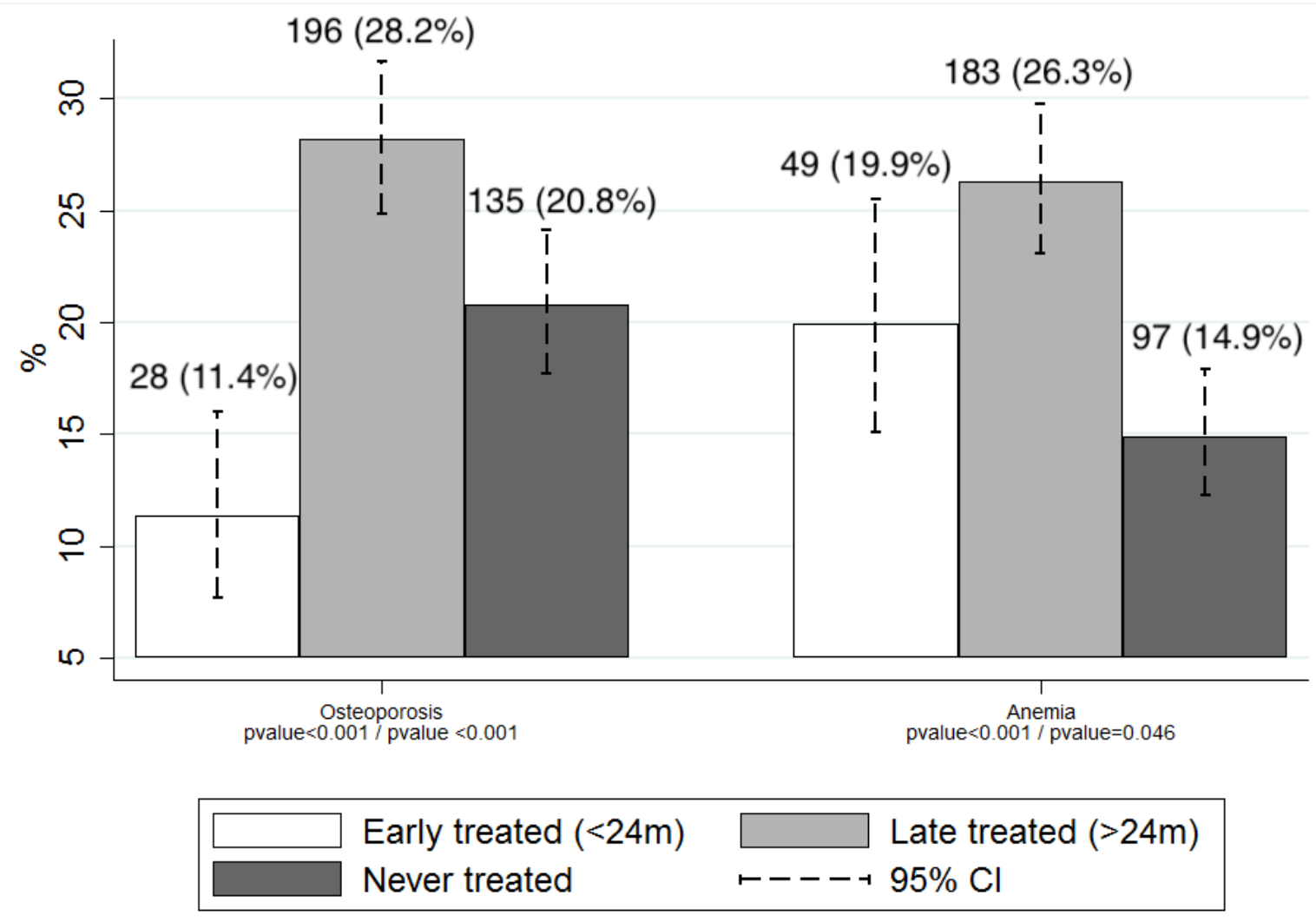

First pvalue refers to overall test; Second pvalue refers to Early vs Late test

Figure 3: Frequency of osteoporosis and anaemia among the different treatment groups. CI: confidence interval 

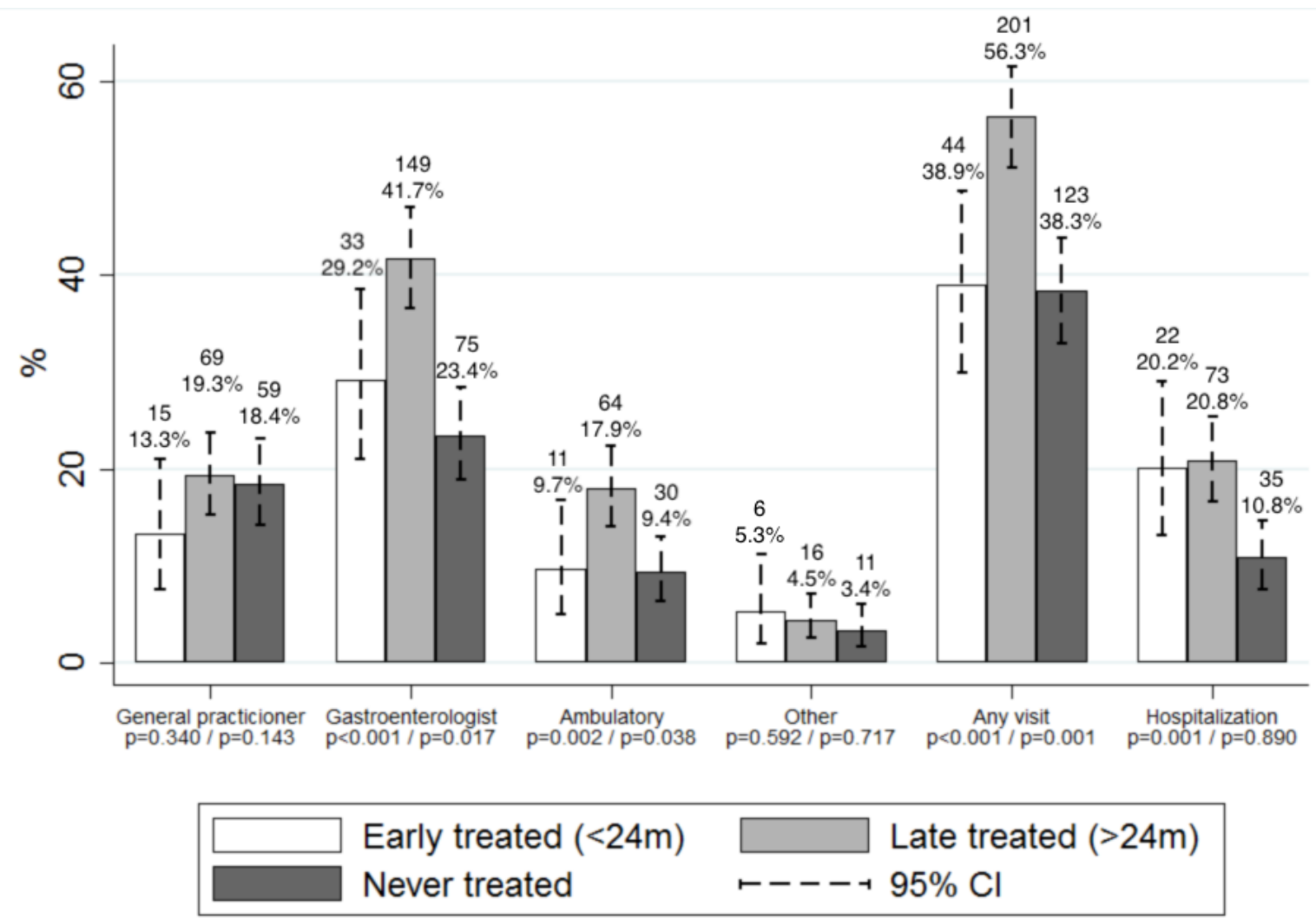

First pvalue refers to overall test; Second pvalue refers to Early vs Late test

Figure 4: Frequency of patients with medical visits and hospitalisations related to IBD among the different treatment groups

CI: confidence interval 
Manuscript Doi: 10.1093/ecco-jcc/jjz057

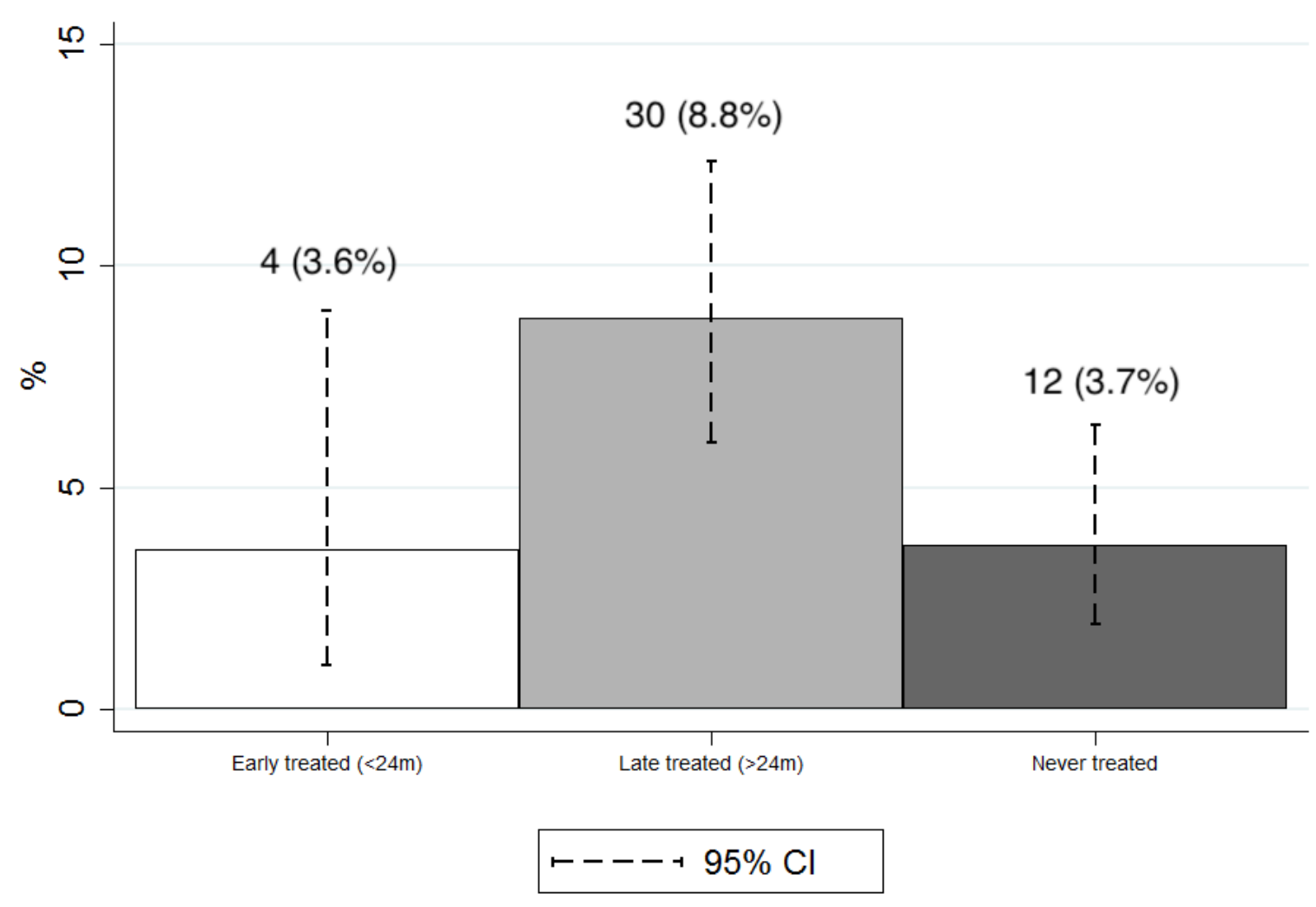

Pvalue overall: $p=0.016$; Pvalue Early vs Late: $p=0.096$.

Figure 5: Percentages of patients with absence from work among the three different treatment groups

CI: confidence interval 


\section{$\underline{\text { Tables }}$}

\begin{tabular}{|c|c|c|c|c|c|}
\hline $\begin{array}{l}\text { Anti-TNF } \\
\text { treatment: }\end{array}$ & $\begin{array}{l}\text { Early } \\
\text { treated } \\
(< \\
24 \text { months })\end{array}$ & $\begin{array}{l}\text { Late treated } \\
(>= \\
\text { 24months })\end{array}$ & $\begin{array}{l}\text { Never } \\
\text { treated }\end{array}$ & $\begin{array}{l}\text { P- } \\
\text { value } \\
\text { global }\end{array}$ & $\begin{array}{l}\text { P-value } \\
\text { early vs. } \\
\text { late }\end{array}$ \\
\hline $\begin{array}{l}\text { Number of } \\
\text { patients }\end{array}$ & 246 & 696 & 650 & & \\
\hline $\begin{array}{l}\text { Gender } \\
\text { Male } \\
\text { Female }\end{array}$ & $\begin{array}{l}124(50.4) \\
122(49.6)\end{array}$ & $\begin{array}{l}323(46.4) \\
373(53.6)\end{array}$ & $\begin{array}{l}309(47.5) \\
341(52.5)\end{array}$ & 0.558 & 0.280 \\
\hline $\begin{array}{l}\text { Age at diagnosis } \\
\text { (years) } \\
\text { (median, IQR, } \\
\text { range) }\end{array}$ & $\begin{array}{l}27,20-38 \\
13-78\end{array}$ & $\begin{array}{l}24,19-32 \\
3-75\end{array}$ & $\begin{array}{l}29,22-41 \\
1-81\end{array}$ & $<0.001$ & $<0.001$ \\
\hline $\begin{array}{l}\text { Age (years) } \\
\text { (median, IQR, } \\
\text { range) }\end{array}$ & $\begin{array}{l}32,26-42 \\
17-88\end{array}$ & $\begin{array}{l}44,34-53 \\
19-85\end{array}$ & $\begin{array}{l}48,36-62 \\
18-89\end{array}$ & $<0.001$ & $<0.001$ \\
\hline $\begin{array}{l}\text { Disease duration } \\
\text { (years) } \\
\text { (median, IQR, } \\
\text { range) }\end{array}$ & $\begin{array}{l}5,3-7 \\
0-16\end{array}$ & $\begin{array}{l}16,11-23 \\
3-47\end{array}$ & $\begin{array}{l}13,6-23 \\
0-57\end{array}$ & $<0.001$ & $<0.001$ \\
\hline $\begin{array}{l}\text { Months since } \\
\text { last reported flare } \\
\text { (median, IQR, } \\
\text { range) }\end{array}$ & $\begin{array}{l}12,4-30 \\
0-60\end{array}$ & $\begin{array}{l}20,8-36 \\
0-74\end{array}$ & $\begin{array}{l}16,6-38 \\
0-77\end{array}$ & 0.041 & 0.011 \\
\hline $\begin{array}{l}\text { CDAI score at } \\
\text { Last Follow-up } \\
\text { (median, IQR, } \\
\text { range) }\end{array}$ & $\begin{array}{l}25,6-54 \\
0-280\end{array}$ & $\begin{array}{l}26,6-60 \\
0-339\end{array}$ & $\begin{array}{l}20,6-46 \\
0-345\end{array}$ & 0.001 & 0.247 \\
\hline $\begin{array}{l}\text { Behaviour } \\
\text { B1 } \\
\text { B1p } \\
\text { B2 } \\
\text { B2p } \\
\text { B3 } \\
\text { B3p } \\
\end{array}$ & $\begin{array}{l}94(38.2) \\
64(26.0) \\
42(17.1) \\
9(3.7) \\
17(6.9) \\
20(8.1)\end{array}$ & $\begin{array}{l}185(26.6) \\
96(13.8) \\
152(21.8) \\
121(17.4) \\
46(6.6) \\
96(13.8)\end{array}$ & $\begin{array}{l}325(50.0) \\
69(10.6) \\
123(18.9) \\
64(9.9) \\
42(6.5) \\
27(4.2) \\
\end{array}$ & $<0.001$ & $<0.001$ \\
\hline $\begin{array}{l}\text { Smoking status at } \\
\text { diagnosis } \\
\text { Non-Smoker } \\
\text { Smoker } \\
\text { Unknown } \\
\end{array}$ & $\begin{array}{l}134(54.5) \\
102(41.5) \\
10(4.0)\end{array}$ & $\begin{array}{l}325(46.7) \\
337(48.4) \\
34(4.9) \\
\end{array}$ & $\begin{array}{l}325(50.0) \\
302(45.5) \\
23(4.5)\end{array}$ & 0.222 & 0.111 \\
\hline $\begin{array}{l}\text { Smoking status at } \\
\text { latest follow-up } \\
\text { Non-Smoker } \\
\text { Smoker } \\
\text { Unknown } \\
\end{array}$ & $\begin{array}{l}163(66.3) \\
81(32.9) \\
2(0.8)\end{array}$ & $\begin{array}{l}455(65.4) \\
238(34.2) \\
3(0.4)\end{array}$ & $\begin{array}{l}462(71.1) \\
181(27.9) \\
7(1.1)\end{array}$ & 0.071 & 0.694 \\
\hline $\begin{array}{l}\text { BMI } \\
\text { (median, IQR, }\end{array}$ & $\begin{array}{l}23.0,20.2- \\
25.6\end{array}$ & $\begin{array}{l}22.9,20.5-26.0 \\
14.7-45.4\end{array}$ & $\begin{array}{l}23.1,20.7- \\
26.0\end{array}$ & 0.307 & 0.794 \\
\hline
\end{tabular}




\begin{tabular}{|l|l|l|l|l|}
\hline range) & $14.6-50.1$ & $13.9-48.1$ & & \\
\hline
\end{tabular}

Table 1: Baseline characteristics and demographic data of study population.

IQR: interquartile range 


\begin{tabular}{|c|c|c|c|}
\hline $\begin{array}{l}\text { Primary } \\
\text { Outcome }\end{array}$ & $\begin{array}{l}\text { Comparison } \\
\text { Early - no pre-existing } \\
\text { c. } \\
\text { vs } \\
\text { Early - pre-existing c. } \\
\text { vs } \\
\text { Late - no pre-existing } \\
\text { c. vs } \\
\text { Late - pre-existing c. } \\
\text { (global test) }\end{array}$ & $\begin{array}{l}\text { Comparison } \\
\text { Early vs } \\
\text { Late }\end{array}$ & $\begin{array}{l}\text { Comparison } \\
\text { Early vs } \\
\text { Late } \\
\text { pre-existing } \\
\text { complication }\end{array}$ \\
\hline Stenosis & $<0.001$ & $<0.001$ & 0.147 \\
\hline $\begin{array}{l}\text { Perianal } \\
\text { fistula }\end{array}$ & 0.506 & 0.671 & 0.560 \\
\hline Other fistula & 0.961 & 0.781 & 0.676 \\
\hline Any fistula & 0.627 & 0.413 & 0.519 \\
\hline $\begin{array}{l}\text { Perianal } \\
\text { surgery }\end{array}$ & 0.002 & 0.935 & 0.846 \\
\hline $\begin{array}{l}\text { Intestinal } \\
\text { surgery }\end{array}$ & 0.623 & 0.213 & 0.607 \\
\hline Any surgery & 0.927 & 0.702 & 0.892 \\
\hline EIM & $<0.001$ & 0.750 & 0.087 \\
\hline
\end{tabular}

Table 2: P-values of primary outcomes using Log-rank tests and Kaplan-Meier analysis 